\title{
Corrosion Behavior of the Ni-Cr-Fe Base Superalloy GH984G in a Synthetic Coal Ash and Flue Gas Environment
}

\author{
Guang-Ming Liu ${ }^{1} \cdot$ Hua-Chun Yang ${ }^{2} \cdot$ Qin Liang $^{2} \cdot$ Xiao-Chuan Yang ${ }^{2} \cdot$ Shan-Ping Ren ${ }^{1} \cdot$ Jian-Hang Huang ${ }^{1}$
}

Received: 16 December 2016/Revised: 22 March 2017/Published online: 22 June 2017

(C) The Chinese Society for Metals and Springer-Verlag GmbH Germany 2017

\begin{abstract}
The corrosion behavior of the new Ni-Cr-Fe base superalloy GH984G in a synthetic coal ash and flue gas environments was studied at $700{ }^{\circ} \mathrm{C}$. The results showed that the corrosion rate was slow during the initial corrosion stage, then followed by a stage of faster mass loss. During the corrosion test, the scale trended to spall slightly, resulting in the formation of corrosion pits on the sample surfaces. The main corrosion products were identified as $\mathrm{NiFeCrO}_{4}$ and a small amount of $\mathrm{Cr}_{2} \mathrm{O}_{3}$. The scale microstructure involved the presence of three corrosion layers. The outer layer contained $\mathrm{Cr}$, $\mathrm{Ni}, \mathrm{Fe}, \mathrm{O}$ and a small amount of $\mathrm{S}$. Many micro-cracks were detected in the Cr-rich intermediate oxide layer. The inner corrosion layer was thin and rich in S. Internal sulfidation and internal oxidation occurred in the substrate. Because of its relatively high $\mathrm{Cr}$ content, the GH984G superalloy exhibited a good corrosion resistance under the test conditions.
\end{abstract}

KEY WORDS: Ni-Fe-Cr base superalloy; Coal ash; $\mathrm{SO}_{2}$; Corrosion

\section{Introduction}

The aim of increasing the efficiency of future coal-fired power plants requires more critical steam conditions. The requirement of high efficiency and reduced emissions requires the use of advanced ultra-supercritical (A-USC) conditions with steam temperatures up to $700-760{ }^{\circ} \mathrm{C}$ and pressures up to $35-37.5 \mathrm{MPa}$ [1-3]. The goal of A-USC is to generate $760{ }^{\circ} \mathrm{C}$ steam, although the metal surface temperature of the key components, including the superheater and reheater tubes will be $800{ }^{\circ} \mathrm{C}$ or even higher [4].

Available online at http://link.springer.com/journal/40195

Guang-Ming Liu gemliu@126.com

1 School of Materials Science and Engineering, Nanchang Hangkong University, Nanchang 330063, China

2 Dongfang Boiler Group Co., Ltd, Material Research Institute, Zigong 643001, China
Ni-based superalloys are expected to be the best candidates for A-USC steam boiler applications in coal-fired power generation systems [5]. The alloy GH984G (Ni-20.7, Fe-20.9, $\mathrm{Cr}-3.4,(\mathrm{Mo}+\mathrm{Nb})-2.3$, (Ti $+\mathrm{Al})-1.4$, wt\%) is a new Ni-FeCr-based wrought superalloy with high creep strength [6, 7]. This superalloy is a candidate for superheater and reheater tubes application due to its comprehensive mechanical properties and long-term thermal stability $[8,9]$. The aim of the present work is to examine the corrosion resistance of this alloy in synthetic flue gases atmosphere at high temperature.

\section{Experimental Procedures}

The alloy GH984 was received from Dongfang Boiler Group Co., Ltd, Material Research Institute. Square specimens with dimensions of $10 \mathrm{~mm} \times 15 \mathrm{~mm} \times 3 \mathrm{~mm}$ were cut by electrical discharge method. The surfaces were ground down to $800 \mathrm{SiC}$ paper. The sample surfaces were cleaned in acetone and distilled water in an ultrasonic bath before testing. The synthetic coal ash powders were prepared from mixture of $\mathrm{Na}_{2} \mathrm{SO}_{4}, \mathrm{~K}_{2} \mathrm{SO}_{4}$ and $\mathrm{Fe}_{2} \mathrm{O}$ with molar ratios of 
3:3:2. The synthetic coal ash suspension was prepared by adding ethanol. Then the samples were placed on a hot plate and coated with the suspension to form a continuous layer of synthetic coal ash with a loading of about $40 \mathrm{mg} / \mathrm{cm}^{2}$. The synthetic flue gas was composed of: $15 \% \mathrm{CO}_{2}, 3.5 \%$ $\mathrm{O}_{2}$, and $0.25 \% \mathrm{SO}_{2}$, and bal. $\mathrm{N}_{2}$. The gas flow was set to a rate of $20 \mathrm{~mL} / \mathrm{min}$, while the test temperature was $700{ }^{\circ} \mathrm{C}$. At selected time intervals, the samples were taken out from the furnace and washed with boiling distilled water, followed by drying and weighing. After this, the samples were coated again with the synthetic coal ash powder and put back into the furnace to continue the test. In order to compare the corrosion resistance of this superalloy with that of other materials, the corrosion kinetics of the other three superalloys $740 \mathrm{H}(\mathrm{Cr}-25.0$, Co-20.0, Mo-0.5, Nb-1.5, Ti1.35, Al-1.35, wt\%),617B (Cr-21.8, Fe-1.3, Mo-9.2, Co12.4, Al-0.92, Ti-0.45, wt\%) and C263 (Cr-20.0, Co-20.0, Mo-6.0, Ti-2.2, Fe-0.55, wt $\%$ ) were tested under the same conditions.

After $1000 \mathrm{~h}$ corrosion test, the surface morphology and phase composition of the corrosion films grown on the sample surfaces were investigated by a scanning electron microscope (SEM) equipped with an energy-dispersive spectroscope (EDS), a three-dimensional optical microscope and by X-ray diffraction (XRD).

\section{Results}

\subsection{Corrosion Kinetics}

Figure 1a compares the corrosion kinetics of GH984G with those of the other three superalloys in the synthetic coal ash/ flue gas environment at $700{ }^{\circ} \mathrm{C}$. The corrosion of the GH984G was slight (about $2.4 \mathrm{mg} / \mathrm{cm}^{2}$ ) in the test conditions for
$1000 \mathrm{~h}$, showing that these alloys exhibit good corrosion resistance in the flue gas environment. The corrosion kinetics of GH984G and $740 \mathrm{H}$ were almost identical. It is noteworthy that the corrosion rate of GH984G was slow during the early corrosion stage $(t<350 \mathrm{~h})$. Conversely, large mass losses were observed for 617B and $\mathrm{C} 263$ during the corrosion test. Furthermore, In particular, 617B suffered from a severe corrosion, with corrosion products spalling extensively from the sample surfaces.

\subsection{Phase Composition and Microstructure of the Corrosion Products}

Figure 2 shows the XRD patterns of GH984G corroded in the synthetic coal ash/flue gas environment at $700{ }^{\circ} \mathrm{C}$. Based on the XRD analysis, the main corrosion products were identified as $\mathrm{NiFeCrO}_{4}$ and a small amount of $\mathrm{Cr}_{2} \mathrm{O}_{3}$.

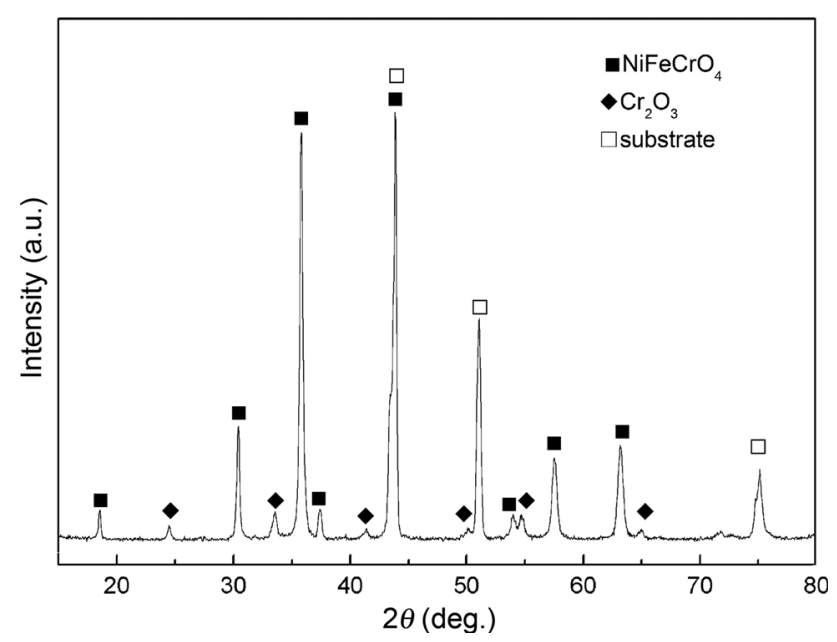

Fig. 2 X-ray diffraction patterns of GH984G after corrosion in the synthetic coal ash/flue gas environment at $700{ }^{\circ} \mathrm{C}$

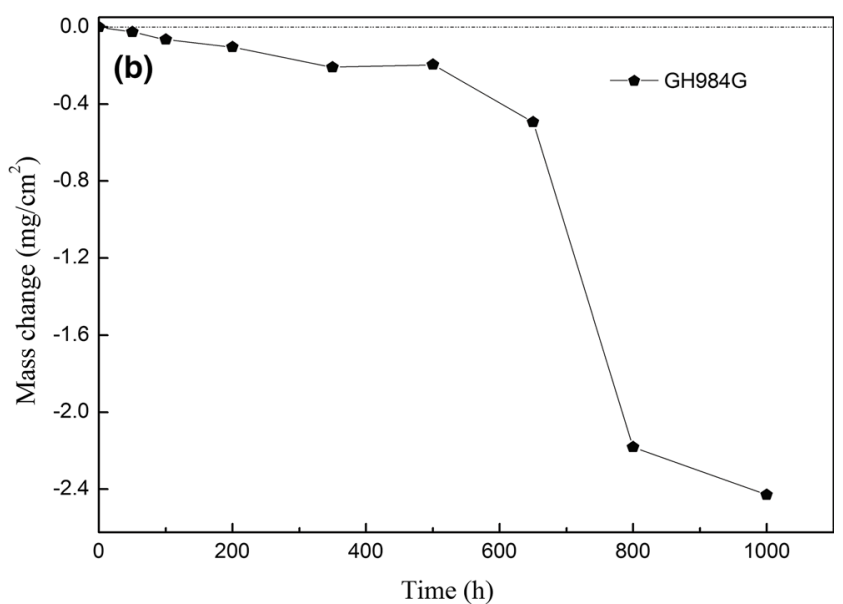

Fig. 1 Mass change per unit surface area for the hot corrosion of $\mathrm{GH} 984 \mathrm{G}$ in the synthetic coal ash/flue gas environment at $700{ }^{\circ} \mathrm{C}$ as a function of time (a for 740H, 617B, C263 and GH984G; b for GH984G) 
Moreover, it is noteworthy that even after $1000 \mathrm{~h}$ corrosion test, strong peaks of substrate were also observed. Combining the results of XRD and the corrosion kinetics, we concluded that the corrosion layer on the sample surface was thin and this alloy had good corrosion resistance.

Figure 3 shows the three-dimensional morphology, surface microstructure and corresponding EDS X-ray spectra of the GH984G alloy after corrosion in the synthetic coal ash/flue gas environment at $700{ }^{\circ} \mathrm{C}$. Many corrosion pits with diameters of 200-300 $\mu \mathrm{m}$ were observed on the corroded sample surface. According to three-dimensional reconstructed image
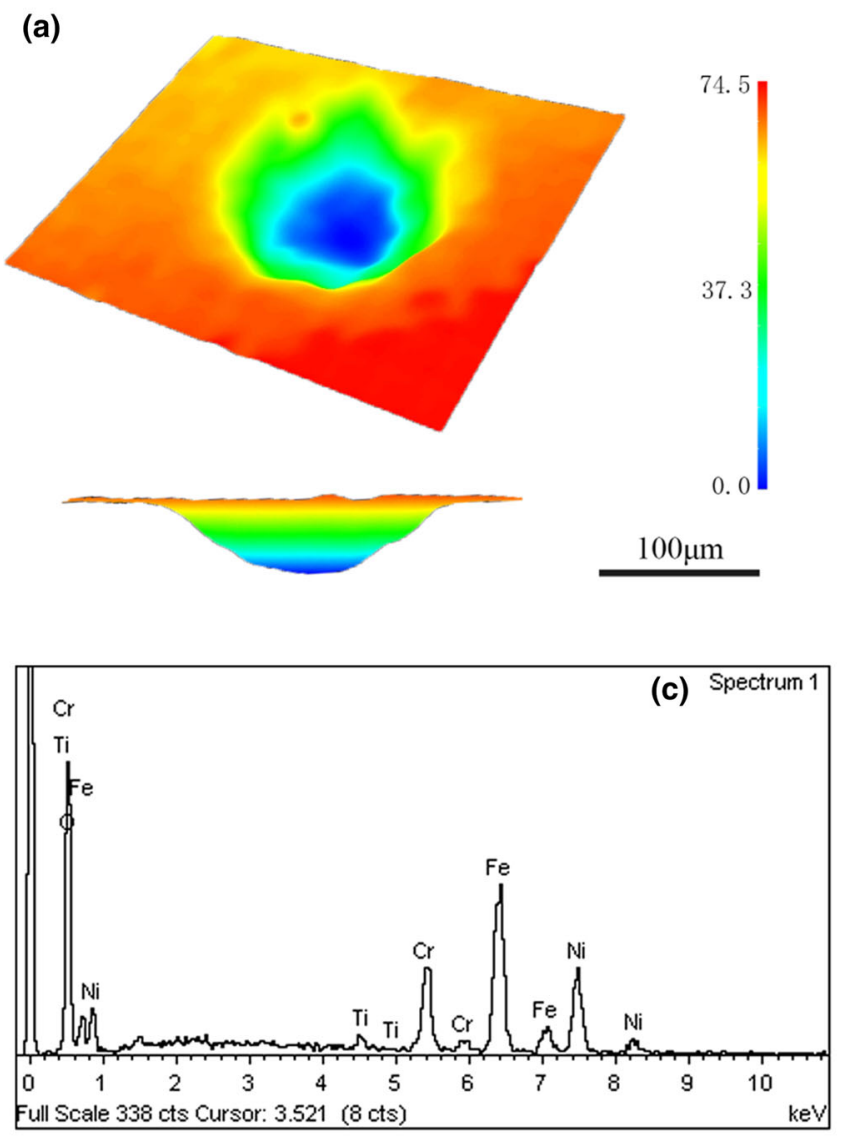

of the pits, the average depth of the pits was about $74 \mu \mathrm{m}$. These pits were originated by spallation of the corrosion products. Actually, the surface morphology around the pits was differentiated into three typical regions. In region 1 , some large grains were observed. The EDS analysis revealed that these large grains were composed of $\mathrm{Fe}, \mathrm{Ni}, \mathrm{Cr}, \mathrm{O}$ and a small amount of Ti. Combining the results of XRD and EDS, we could reasonably conclude that these grains were mainly composed of $\mathrm{NiFeCrO}_{4}$, and $\mathrm{Cr}_{2} \mathrm{O}_{3}$. At places where the corrosion layer of region 1 spalled, region 2 and 3 became exposed. Many pores were detected in region 3 . The EDS
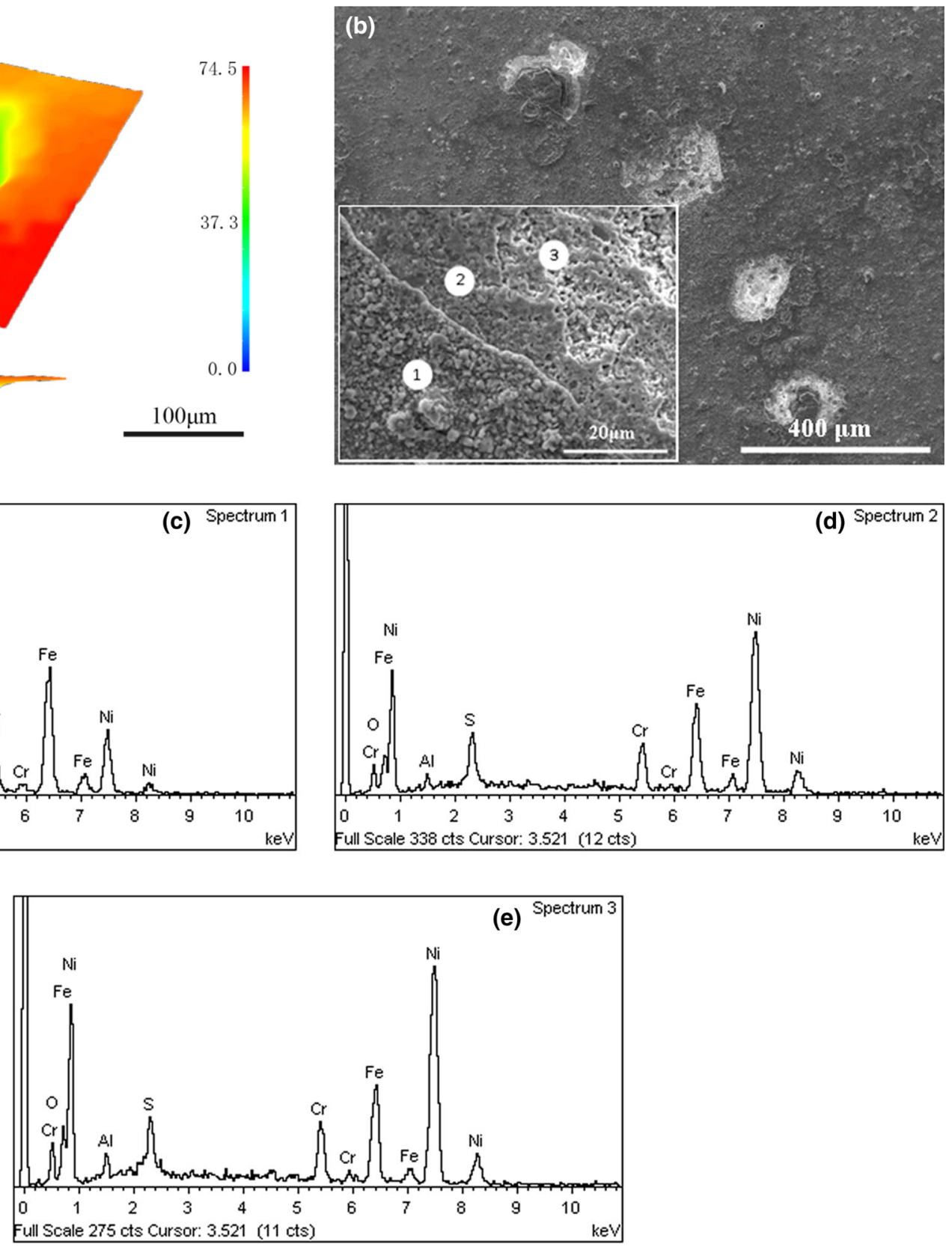

Fig. 3 Three-dimensional morphology a, surface microstructure b. corresponding EDS X-ray spectra c-e of the GH984G alloy after corrosion for $1000 \mathrm{~h}$ 

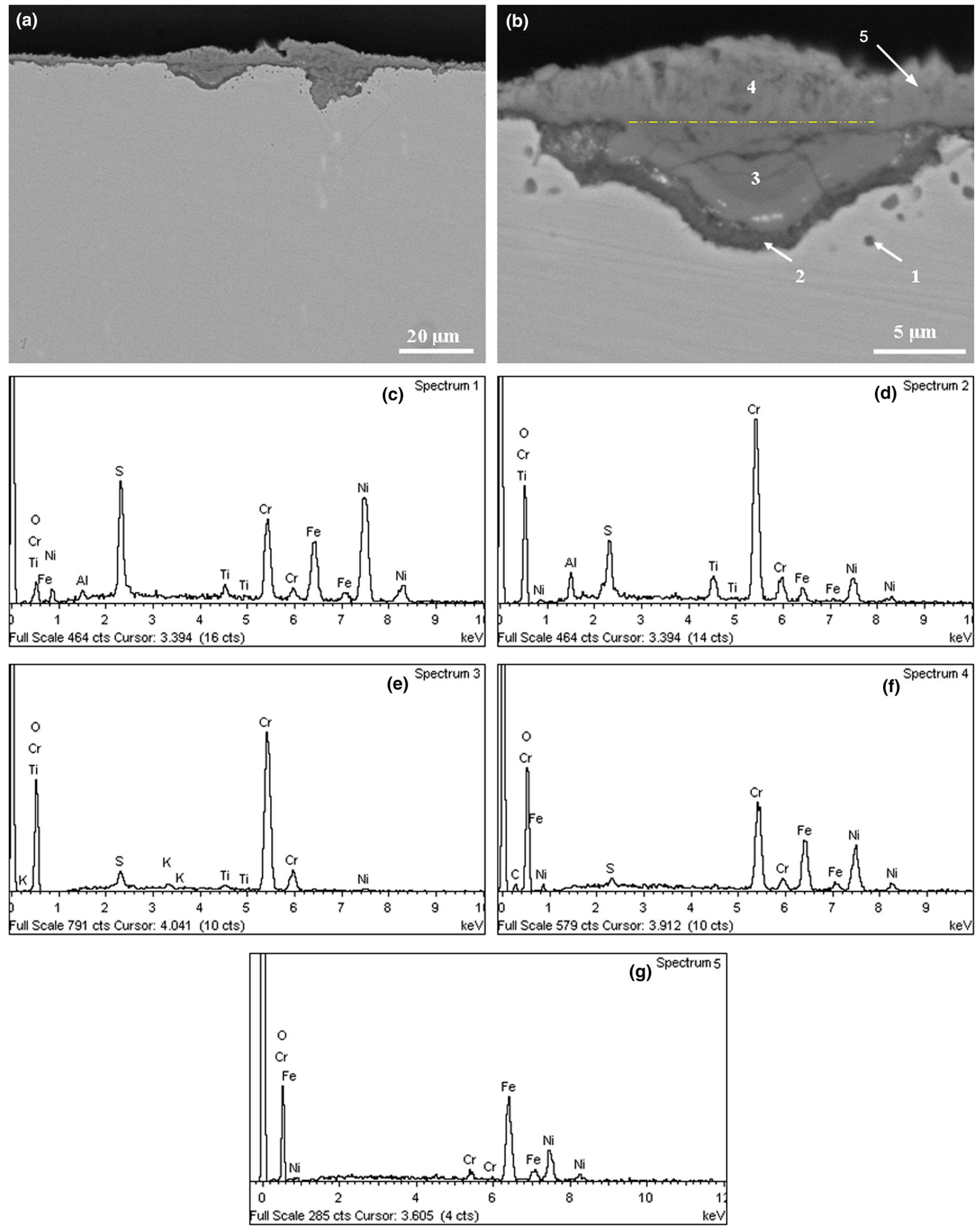

Fig. 4 Cross sections a, b, the corresponding EDS patterns $\mathbf{c}-\mathbf{g}$ of GH984G after corrosion 
analysis revealed that regions 2 and 3 were composed of $\mathrm{Ni}$, $\mathrm{Fe}, \mathrm{Cr}, \mathrm{Al}, \mathrm{O}$ and $\mathrm{S}$, indicating that sulfides formed under the outer corrosion layer.

Figure $4 \mathrm{a}, \mathrm{b}$ shows the cross-sectional microstructures of the GH984G alloy after corrosion in the synthetic coal ash/flue gas environment at $700{ }^{\circ} \mathrm{C}$. In Fig. 4a, SEM observation showed that the corrosion layer has an average thickness of about 3-5 $\mu \mathrm{m}$. Moreover, some corrosion pits with a depth of 15-20 $\mu \mathrm{m}$ filled with corrosion products were detected. Figure $4 \mathrm{~b}$ is a higher magnification of the corrosion pit in Fig. 4a. In Fig. 4b, the SEM observations revealed that the scale was composed of three layers. The outer layer was compact, and the EDS analysis showed that it contained $\mathrm{Cr}, \mathrm{Ni}, \mathrm{Fe}, \mathrm{O}$ and a small amount of $\mathrm{S}$. The intermediate layer presented many micro-cracks, and according to the EDS analysis, this layer contained $\mathrm{Cr}$ and $\mathrm{O}$ and a small amount of $\mathrm{S}$. The inner layer was very thin and rich in S by the EDS analysis. It is noteworthy that the substrate presented some dark gray sites rich in $\mathrm{S}$ and $\mathrm{O}$, showing that internal oxidation and sulfidation occurred.

\section{Discussion}

The corrosion rate of boiler superheaters and reheaters is accelerated when sodium sulfate, potassium sulfate, and iron sulfate are deposited on their surfaces. It is reported that the melting point of the ternary sulfate $(\mathrm{Na}, \mathrm{K})_{3-}$ $\mathrm{Fe}\left(\mathrm{SO}_{4}\right)_{3}$ is $560{ }^{\circ} \mathrm{C}$ when the mole ratio of $\mathrm{Na}: \mathrm{K}$ is $1: 1$ [10]. However, high concentrations of $\mathrm{SO}_{3}$ are required to form the low melting point ternary sulfate [11]. In this experiment, only $\mathrm{SO}_{2}$ was introduced instead of $\mathrm{SO}_{3}$. However, $\mathrm{SO}_{2}$ may react with $\mathrm{O}_{2}$ to form $\mathrm{SO}_{3}$. The presence of a catalyst (such as $\mathrm{Pt}, \mathrm{Fe}$ ) in the environment tends to accelerate the conversion rate of $\mathrm{SO}_{2}$ to $\mathrm{SO}_{3}$. Generally, $\mathrm{Fe}_{2} \mathrm{O}_{3}$ existing in the synthetic coal ash, as well as the oxides $\mathrm{Fe}_{2} \mathrm{O}_{3}$ or $\mathrm{NiO}$ formed in scale could act as catalysts for this reaction. Furthermore, $\mathrm{SO}_{3}$ could also be produced from the decomposition of sulfates at high temperatures. Therefore, the concentration of $\mathrm{SO}_{3}$ on the sample surface might be high enough to form low melting point multiple sulfates over some restricted regions. In addition, the thermodynamic phase diagram of the $\mathrm{Ni}-\mathrm{S}-\mathrm{O}$ system indicated that $\mathrm{NiSO}_{4}$ is stable under experiment condition, suggesting the possibility of formation of the double sulfate $\mathrm{Na}_{2} \mathrm{SO}_{4}-\mathrm{NiSO}_{4}$ with a low a melting points $\left(67{ }^{\circ} \mathrm{C}\right)$ [12]. Therefore, low melting point molten sulfates could be formed locally on the sample surface at $700{ }^{\circ} \mathrm{C}$. According to the experiment results, GH984G showed good corrosion resistance after $1000 \mathrm{~h}$ test, with only some corrosion pits on the sample surface. This could be ascribed to the fact that molten salts formed only in some local regions, not on the whole sample surface. In these local regions, the corrosion rate accelerated, while corrosion products spalled during the test. Moreover, the presence of $\mathrm{Al}_{2} \mathrm{O}_{3}$ and $\mathrm{Cr}_{2} \mathrm{O}_{3}$ in the oxide layer was not favorable to the formation of stable sulfates under our experimental conditions [12], which could have contributed to inhibit severe hot corrosion.

During the initial corrosion stage, a $\mathrm{Cr}_{2} \mathrm{O}_{3}$-rich oxide film was probably formed rapidly on the sample surface because of the high $\mathrm{Cr}$ content of the alloy [13]. Moreover, $\mathrm{Ti}$ and $\mathrm{Al}$ could have easily formed the corresponding oxides due to their high affinity to O. Generally, Ti may diffuse rapidly outward, forming titanium oxide in the outer corrosion layer. On the contrary, the rate of outward diffusion of $\mathrm{Al}$ is slower than that of $\mathrm{Ti}$. Therefore, alumina was enriched in the inner corrosion layer [14, 15], possibly contributing to inhibit the hot corrosion of the substrate. In addition, as mentioned above, a $\mathrm{Cr}_{2} \mathrm{O}_{3}$-rich oxide layer formed initially on the sample surface. Therefore, the corrosion rate was relatively slow during the initial corrosion stage $(t<350 \mathrm{~h})$.

With an increase in the oxide layer thickness, the oxygen partial pressure in the oxide layer is much lower than that of flue gas environment. Under this condition, S might diffuse inward through the external corrosion layer, leading to a high activity of sulfur in the inner region of the corrosion layer. $\mathrm{S}$ is expected to react preferentially with $\mathrm{Cr}$ than that of Fe, Ni [16]. Then the sulfide would migrate outward and react with oxygen according to following reaction:

$2 \mathrm{CrS}+3 / 2 \mathrm{O}_{2}=\mathrm{Cr}_{2} \mathrm{O}_{3}+\mathrm{S}_{2}$.

A rather porous $\mathrm{Cr}_{2} \mathrm{O}_{3}$ layer formed on the sample surface. The free $\mathrm{S}$ produced in this way may penetrate inward again to form new sulfide. The fact that the inner layer was rich in $\mathrm{S}$ might be related to the above reactions. The formation of sulfide in the corrosion layer may produce more defects in the corrosion layer, which can favor a fast diffusion outward of $\mathrm{Ni}$ and $\mathrm{Fe}$. Under this condition, the corrosion rate accelerated after the initial corrosion stage. This is the reason that the EDS analysis could detect $\mathrm{Ni}$ and $\mathrm{Fe}$ in the outer corrosion layer.

\section{Conclusions}

1. The alloy GH984G showed good corrosion resistance in the synthetic coal ash and flue gas environments at $700{ }^{\circ} \mathrm{C}$ for $1000 \mathrm{~h}$.

2. During the initial corrosion stage, the corrosion rate was slow and then followed faster mass loss. Many corrosion pits formed on the sample surface, which originated from the spallation of the corrosion products. The main corrosion products were $\mathrm{NiFeCrO}_{4}$ and a small amount of $\mathrm{Cr}_{2} \mathrm{O}_{3}$. 
3. The corrosion layer was composed of three had layers. An S-rich layer formed at the interface between the external corrosion layer and the metal substrate. Internal sulfidation and internal oxidation occurred in the substrate.

Acknowledgements This work was financially supported by National Science Foundation of China (Grant No. 51161022) and the Science and Technology Foundation of Department of Education of Jiangxi Province, China (Nos. DB201301133, 201301050).

\section{References}

[1] A.H.V. Pavan, K.S.N. Vikrant, R. Ravibharath, K. Singh, Mater. Sci. Eng. A 642, 32 (2015)

[2] F. Sun, Y.F. Gu, J.B. Yan, Z.H. Zhong, M. Yuyama, Acta Mater. 102, 70 (2016)

[3] Z.H. Zhong, Y.F. Gu, Y. Yuan, Z. Shi, Mater. Lett. 109, 38 (2013)
[4] R. Viswanathan, J.F. Henry, J. Tanzosh, G. Stanko, J. Shingledecker, B. Vitalis, R. Purgert, J. Mater. Eng. Perform. 10, 2904 (2013)

[5] N.N. Aung, X.B. Liu, Corros. Sci. 82, 227 (2014)

[6] C. Wang, Y. Guo, J. Guo, L. Zhou, Mater. Des. 88, 790 (2015)

[7] J. Guo, X. Du, Acta Metall. Sin. 41, 1221 (2005) (in Chinese)

[8] C. Wang, T. Wang, M. Tan, Y. Guo, J. Guo, L. Zhou, J. Mater. Sci. Technol. 31, 135 (2015)

[9] T. Wang, C. Wang, W. Sun, X. Qin, J. Guo, L. Zhou, Mater. Des. 62, 225 (2014)

[10] S. Zhao, X. Xie, G.D. Smith, Chin. J. Nonferrous Met. 14, 340 (2004)

[11] Y. Zhang, L. Shi, J. Chin. Soc. Corros. Prot. 12, 20 (1992)

[12] T. Li, High Temperature Oxidation and Hot Corrosion of Metals (Chemical Industry Press, Beijing, 2003)

[13] G. Liu, C. Wang, F. Yu, J. Tian, Oxid. Met. 81, 383 (2013)

[14] F. Abe, H. Araki, H. Yoshida, M. Okada, Oxid. Met. 27, 21 (1987)

[15] D.J. Cherniak, E.B. Watson, D.A. Wark, Chem. Geol. 236, 65 (2007)

[16] Y. Huang, L. Sun, Z. Xu, Y. Han, S. Shi, J. Chin. Soc. Corros. Prot. 11, 255 (1991) 